\section{Pacific Northwest}

National Laboratory

Operated by Battelle for the

U.S. Department of Energy

\title{
Proof-of-Principle Measurements on Unirradiated Zirconium Alloys
}

DC Gerlach

MR Mitchell

BD Reid

April 2007
CJ Gesh

DE Hurley 


\section{DISCLAIMER}

This report was prepared as an account of work sponsored by an agency of the United States Government. Neither the United States Government nor any agency thereof, nor Battelle Memorial Institute, nor any of their employees, makes any warranty, express or implied, or assumes any legal liability or responsibility for the accuracy, completeness, or usefulness of any information, apparatus, product, or process disclosed, or represents that its use would not infringe privately owned rights. Reference herein to any specific commercial product, process, or service by trade name, trademark, manufacturer, or otherwise does not necessarily constitute or imply its endorsement, recommendation, or favoring by the United States Government or any agency thereof, or Battelle Memorial Institute. The views and opinions of authors expressed herein do not necessarily state or reflect those of the United States Government or any agency thereof.

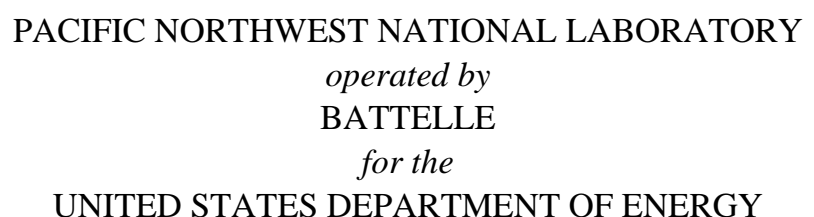
under Contract DE-ACO5-76RL01830

Printed in the United States of America

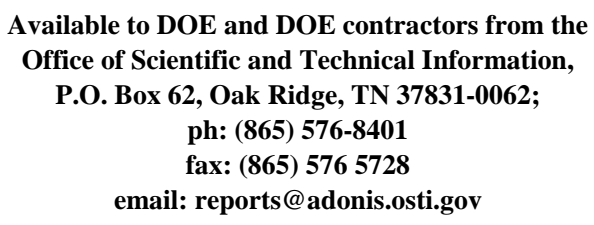

Available to the public from the National Technical Information Service, U.S. Department of Commerce, 5285 Port Royal Rd., Springfield, VA 22161 ph: (800) 553-6847 fax: (703) 605-6900

email: orders@nits.fedworld.gov online ordering: http://www.ntis.gov/ordering.htm 
PNNL-16539

PL06-SOP531-PD09/Task 8

\title{
Proof-of-Principle Measurements on Unirradiated Zirconium Alloys
}

\author{
David C. Gerlach \\ Mark R. Mitchell \\ Bruce D. Reid \\ Christopher J. Gesh \\ David E. Hurley
}

April 2007

Work performed for the

Office of Defense Nuclear Nonproliferation (NA-20)

Office of Nonproliferation Research and Development (NA-22)

Prepared for the U.S. Department of Energy

under Contract DE-AC05-76RL01830

Pacific Northwest National Laboratory

Richland, Washington 99352 



\section{Summary}

The ability to determine fuel assembly burnup has important non-proliferation implications since proliferation activities involve irradiating fuel assemblies to a much lower level of burnup than is normal in commercial Light Water Reactor (LWR) practice, and/or irradiation of separate targets. Similarly, a method of determining burnup could be used to confirm declared operation for a reactor that is operating under IAEA safeguards. It is possible to estimate fuel assembly burnup by measuring gamma and neutron radiation from spent fuel. However, the accuracy of these measurements depends on fission product gamma ray emission ratios that decay with relatively short half-lives. The use of isotope ratio measurements to measure the level of neutron exposure that material has received has been very well demonstrated for samples of high-purity graphite and aluminum alloys (Cliff et al. 2005; Gesh 2004; Gerlach et al. 2006). The current project is an attempt to demonstrate that isotope ratio measurements can be extended to zirconium alloys used in LWR fuel assemblies. Zirconium alloys are used for structural elements of fuel assemblies and for the fuel element cladding. This report covers proof-of-principle measurements done on unirradiated zirconium alloys, and resulting measurements show that:

1. Titanium 48/Titanium 49 ratios can be measured in zirconium alloys using a Secondary Ionization Mass Spectrometer (SIMS) - enough titanium was present in each of six samples tried to allow correction of interfering ions.

2. The Ti 48/49 ratio measured in unirradiated zirconium alloy is, within a narrow error band, the same as that found in natural, unirradiated zirconium, and suggests that the natural Ti ratios can be assumed to be the initial starting values before irradiation. 



\section{Abbreviations and Acronyms}

$\begin{array}{ll}\mathrm{Cr} & \text { Chromium } \\ \mathrm{In} & \text { Indium } \\ \mathrm{LWR} & \text { Light Water Reactor } \\ \mathrm{Nb} & \text { Niobium } \\ \mathrm{PNNL} & \text { Pacific Northwest National Laboratory } \\ \mathrm{SIMS} & \text { Secondary Ionization Mass Spectrometry } \\ \mathrm{Ti} & \text { Titanium } \\ \mathrm{Th} & \text { Thorium } \\ \mathrm{U} & \text { Uranium } \\ \mathrm{V} & \text { Vanadium } \\ \mathrm{Zr}-2 & \text { Zircaloy-2 } \\ \mathrm{Zr}-4 & \text { Zircaloy-4 } \\ \mathrm{Zr} & \text { Zirconium }\end{array}$





\section{Contents}

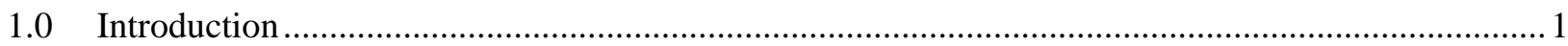

2.0 Secondary Ionization Mass Spectrometric (SIMS) Analysis of Zircaloys....................................... 1

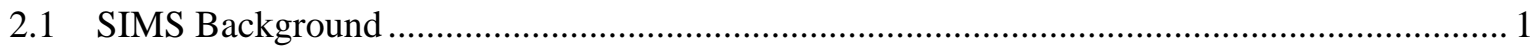

2.2 SIMS Approaches for Analysis of Zircaloy Samples........................................................... 2

2.3 SIMS Measurement of Ti Isotope Ratios in Unirradiated Zircaloy Samples ........................... 4

2.4 Preliminary Measurements of Ti isotope Ratios in Irradiated Zircaloy ................................. 6

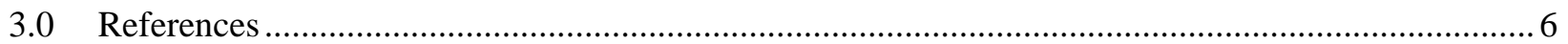

\section{Figures}

1. SIMS Mass Scan from $\mathrm{H}$ to $>$ Pu Mass Range, Showing Matrix Elements, and Major Interferences Arising from Zr and the SIMS Primary Oxygen Ion Beam ................................. 2

2. SIMS Mass Scan from H through Transition Metals ...................................................................... 3

3. SIMS Mass Scan from Sc to Ti, Showing Ti Masses and $\mathrm{Zr}^{+2}$ Interferences.................................... 3

4. Typical SIMS Isotope Ratio Data Acquisition for Ti Isotopes, with ${ }^{91} \mathrm{Zr}^{+2}$ Ions Included, and Excluding Ions at Mass 50, due to Cr and V Interferences

\section{Tables}

1. Uncorrected and Corrected SIMS ${ }^{49} \mathrm{Ti} /{ }^{48} \mathrm{Ti}$ Ratios in 6 Samples of Zircaloy...................................... 5 



\subsection{Introduction}

This report describes progress in Secondary Ionization Mass Spectrometry (SIMS) measurements of ${ }^{49} \mathrm{Ti} /{ }^{48} \mathrm{Ti}$ ratios in unirradiated zirconium alloys, specifically Zircaloy-2 (Zr-2), Zircaloy-4 (Zr-4) and ZrNiobium. The level of Ti impurity varies randomly from batch to batch of zircaloy. However, the absolute quantity of titanium does not affect the accuracy of isotope ratio measurements, so long as there is a measurable ion signal using the SIMS.

\subsection{Secondary Ionization Mass Spectrometric (SIMS) Analysis of Zircaloys}

\subsection{SIMS Background}

Secondary ionization mass spectrometry (SIMS) analysis is a mature and highly successful analytical method, is usually conducted directly on samples with little or no preparation or separation chemistry, and offers advantages of quick turnaround compared to other mass spectrometric analysis methods requiring time- and labor-intensive preparation. SIMS analysis employs a focused beam of high-energy primary ions directly bombarding the sample surface to sputter the sample and is capable of high spatial resolution compared to laser ablation. Transfer of energy and momentum results in ejection of neutral and charged particles (ions to complex molecules), and this removal is called sputtering.

In further contrast to other mass spectrometric analysis methods, SIMS is capable of microscopic physical spatial resolution in addition to elemental or isotopic analysis. This is due both to the spatial resolution afforded by using a primary ion beam for initial sputtering and the secondary ion optics. Some ion beams can sample small areas down to 1 micron in diameter, a much smaller spot size than achievable by laser ablation. A typical SIMS instrument is designed with astigmatic spherical ion optics so that relative positions of all secondary ions from a given area on the sample surface are preserved when reaching an ion imaging detector. Spatial resolution provided by SIMS results in analysis of microscopic features in a sample material or microscopic objects, and evaluation of microscopic elemental and isotopic heterogeneity in a very small area (micron-scale) with either ion counting detectors or ion imaging detectors.

The detection efficiency for SIMS is comparable to, or better than most, other mass spectrometers, but may vary with element and the sample matrix containing the element of interest. The amount of sample consumed by the SIMS primary ion beam may be very small, less than a few cubic microns. Production of secondary ions from a sample depends to a large extent on the electron affinity (for negative ions) and the first ionization potential (for positive ions) of the element of interest. Sample matrix effects in SIMS analysis can affect secondary ionization of the element and concentration determinations, and matrix-matched standards are usually employed. Matrix effects must be accounted for when measuring inter-element ratios such as U/Th, but are of little concern for analysis of isotope ratios. As in other mass spectrometers, molecular and isobaric interferences must be avoided or considered during SIMS analysis. 


\subsection{SIMS Approaches for Analysis of Zircaloy Samples}

The project aims involve analysis of changing isotope ratios of selected impurity elements in irradiated Zircaloy samples. The Zircaloy sample matrix affords a high sputtered ion yield, providing good detection capability with minimal sample consumption. Minimal sample sizes may be utilized to reduce levels of radiation during handling, transfer, and analysis of irradiated samples.

Zircaloy-2 (Zr-2) consists of 98.25 weight \% zirconium with $1.45 \%$ tin, $0.10 \%$ chromium, 0.135\% iron, $0.055 \%$ nickel and $0.01 \%$ hafnium. Other sources specify Zircaloy-2 as zirconium with $1.20-1.70 \%$ tin, $0.07-0.20 \%$ iron, $0.05-0.15 \%$ chromium, and $0.03-0.08 \%$ nickel, with tin content at the lower and the iron/chromium/nickel content at the higher end of the specification. Zircaloy-4 (Zr-4) consists of 98.23 weight \% zirconium with $1.45 \%$ tin, $0.21 \%$ iron, $0.1 \%$ chromium, and $0.01 \%$ hafnium. Two additional samples in this study are ZrNb alloys, where the $\mathrm{Zr}$ is replaced by 2.5 to $3 \% \mathrm{Nb}$

Initial studies were conducted on 'cold' samples. A total of six samples of different Zircaloys were obtained from PNNL colleagues and from Teledyne Wah Chang Albany in Oregon. To determine the presence of impurity elements and to assess molecular interferences arising from interactions of sample matrix elements ( $\mathrm{Zr}, \mathrm{Nb}$ mainly) with the SIMS primary ion beam $\left(\mathrm{O}_{2}{ }^{+}\right.$ions were used), scans of the mass spectrum were done on samples. Several examples are shown in Figures 1-3, beginning with an overall scan from $\mathrm{H}$ to $\mathrm{Pu}$, and ending with a scan more focused on the Ti isotope mass range.

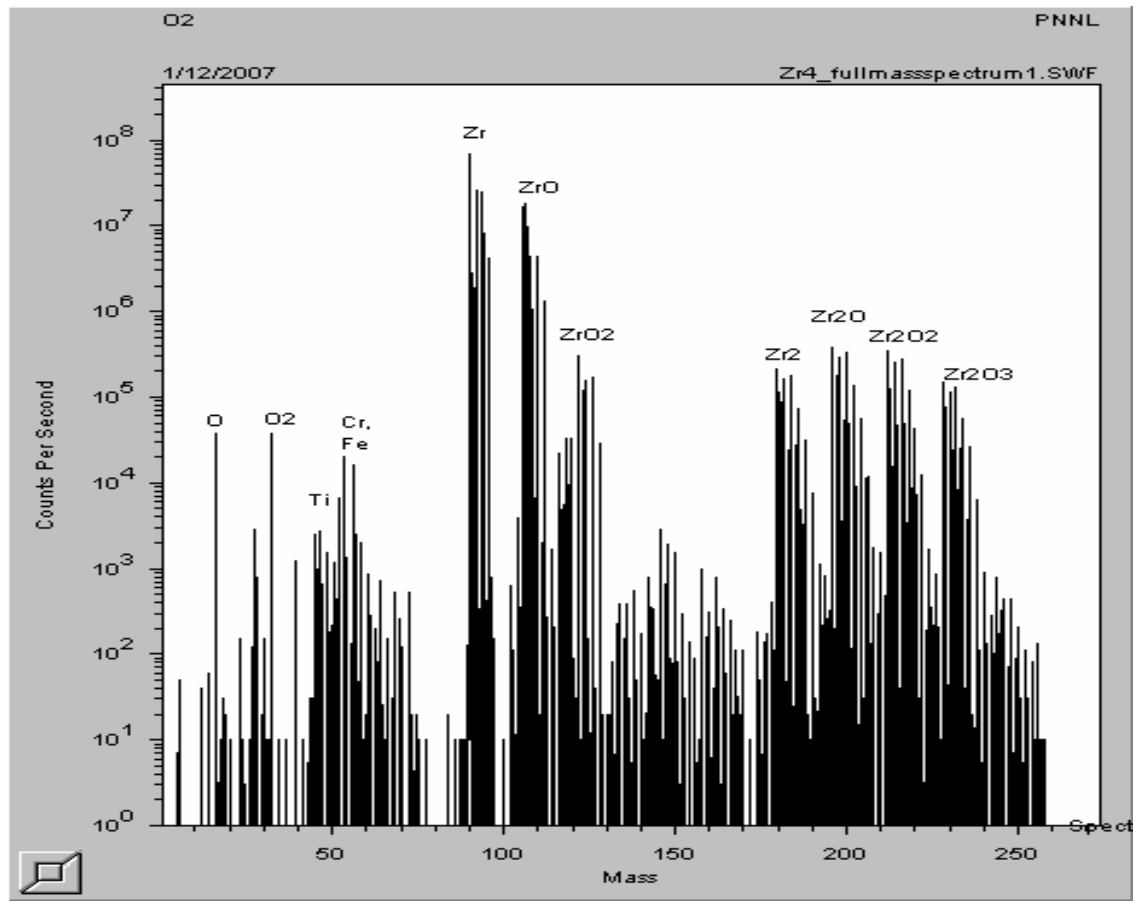

Figure 1. SIMS Mass Scan from $H$ to $>$ Pu Mass Range, Showing Matrix Elements (Zr), and Major Interferences Arising from $\mathrm{Zr}$ and the SIMS Primary Oxygen Ion Beam 


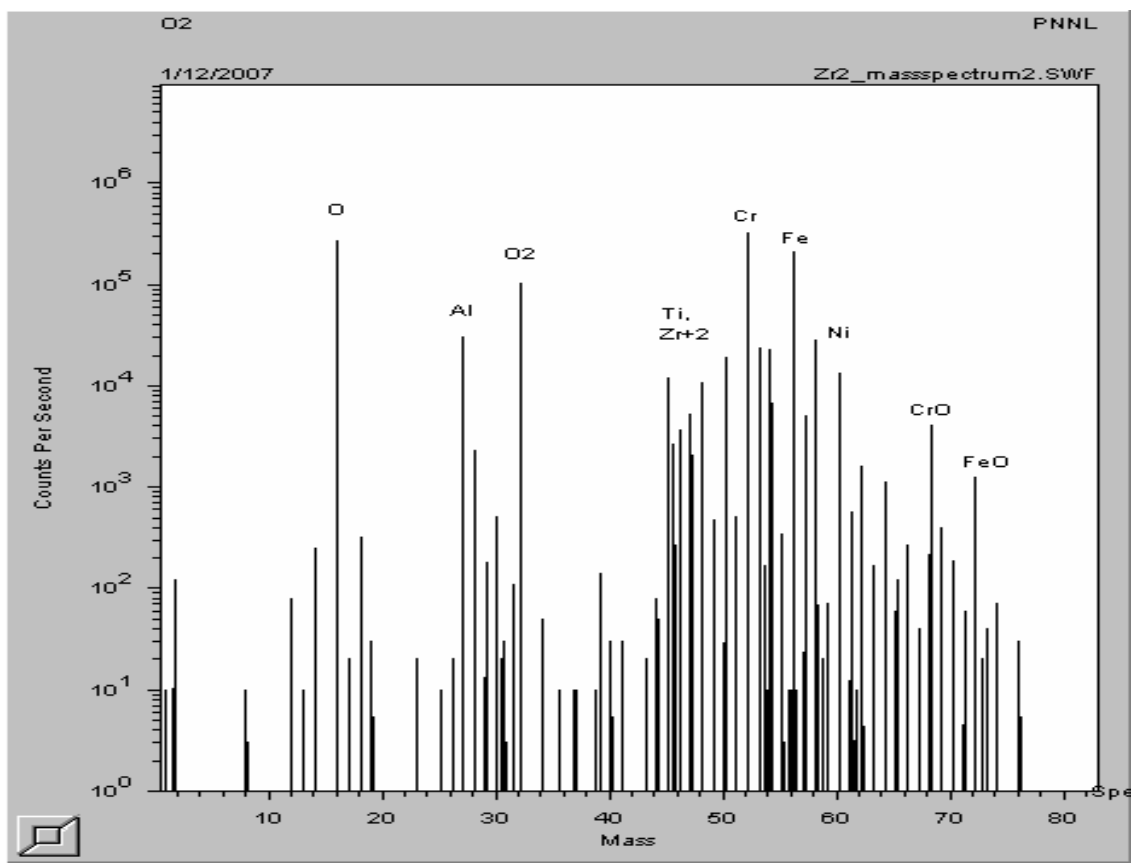

Figure 2. SIMS Mass Scan from H through Transition Metals. Chromium, Fe, and Ni are major constituents.

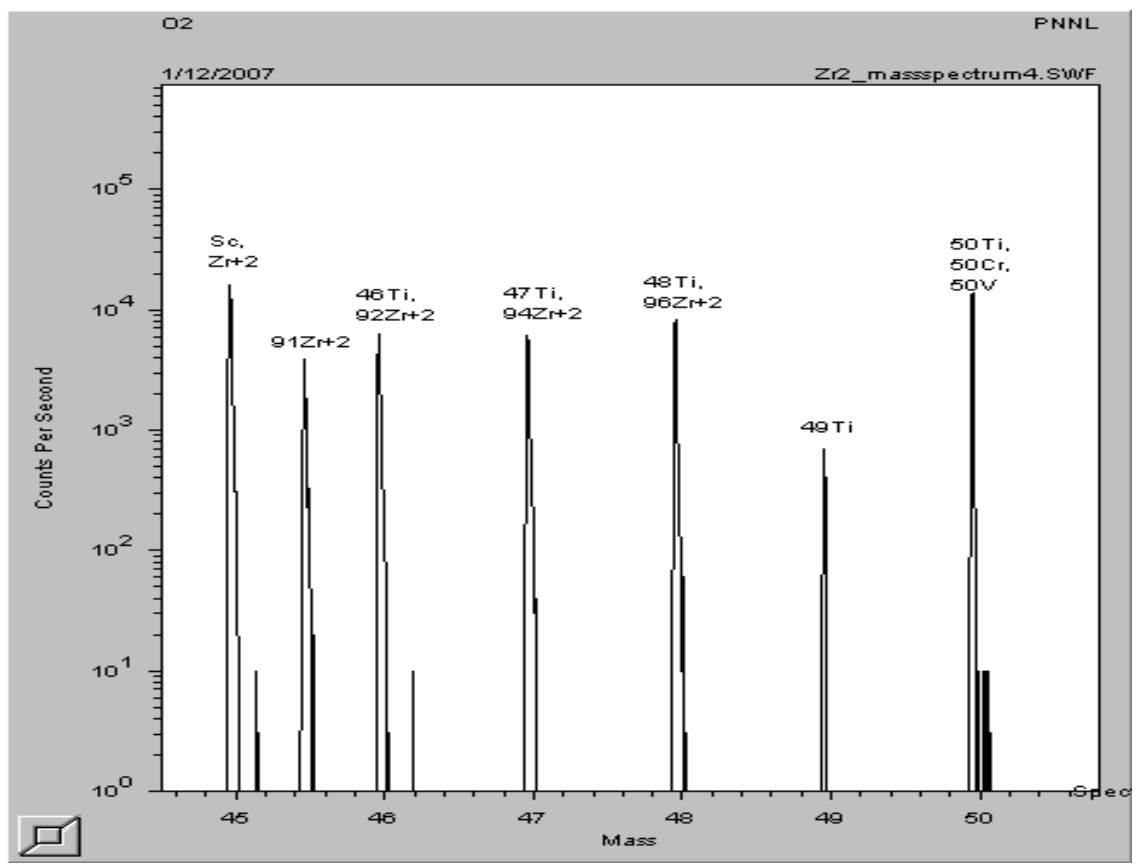

Figure 3. SIMS Mass Scan from Sc to Ti, Showing Ti Masses and $\mathrm{Zr}^{+2}$ Interferences 


\subsection{SIMS Measurement of Ti Isotope Ratios in Unirradiated Zircaloy Samples}

Because it varies strongly with irradiation, is reasonably easy to resolve using the SIMS technique, the most useful isotope ratio identified so far for determining irradiation levels is ${ }^{49} \mathrm{Ti} /{ }^{48} \mathrm{Ti}$. Previous project work at PNNL revealed that titanium is a useful impurity to study when looking for fluence indicators; the ranges of neutron fluence exposure and fuel burnup wherein this ratio is useful was also determined (Reid et al. 2001). Other Ti isotopes (e.g., ${ }^{46} \mathrm{Ti} /{ }^{48} \mathrm{Ti},{ }^{47} \mathrm{Ti} /{ }^{48} \mathrm{Ti}$ ) change much more slowly with burnup and are not very useful, or have isobaric interference with other impurity elements $\left({ }^{50} \mathrm{Ti}\right.$ vs. ${ }^{50} \mathrm{~V}$ vs. ${ }^{50} \mathrm{Cr}$ ). This latter type of interference is shown in Figure 3, and additional interferences arising from doubly charged $\mathrm{Zr}$ ions present at mass 46,47 , and 48 . $\mathrm{The}^{91} \mathrm{Zr}^{+2}$ interference gives rise to a very constant and stable ion signal occurring at an easily resolved half-mass position. This interference is included in each analysis to correct the ${ }^{48} \mathrm{Ti}$ ion count rate by subtracting the signal from the doubly charged ${ }^{96} \mathrm{Zr}^{+2}$ ions (which have the same charge-to-mass ratio). A graphical example of a single Ti isotope ratio SIMS analysis is shown in Figure 4.

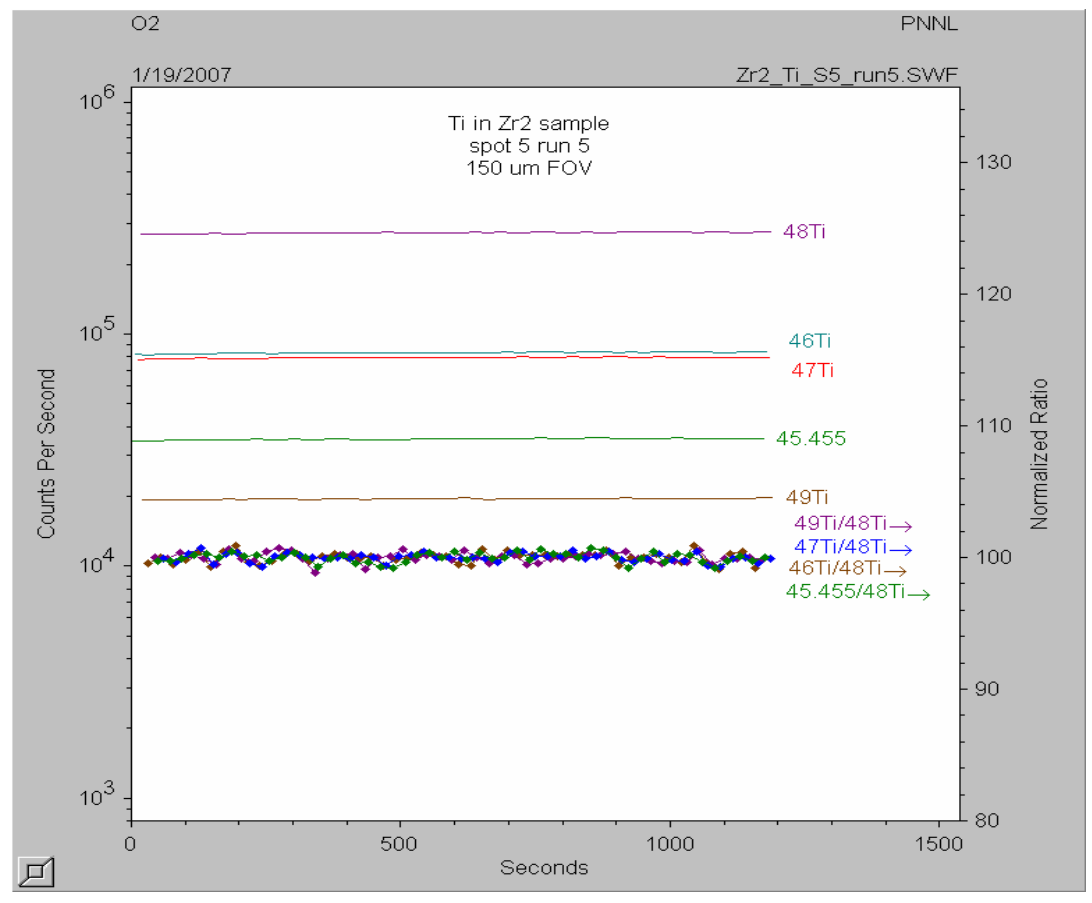

Figure 4. Typical SIMS Isotope Ratio Data Acquisition for Ti Isotopes, with ${ }^{91} \mathrm{Zr}^{+2}$ Ions Included (mass 45.455), and Excluding Ions at Mass 50, due to Cr and V Interferences

In this example (Figure 4), the ion count rates (left-hand y axis) are shown along with the ion count rate for the half-mass ${ }^{91} \mathrm{Zr}^{+2}$ interference. All Ti ion count rates except for ${ }^{49} \mathrm{Ti}$ are higher due to other $\mathrm{Zr}^{+2}$ interferences, e.g., ${ }^{92} \mathrm{Zr}^{+2}$ at mass 46, etc. (Both zirconium 91 and zirconium 96 were present in the sample and each presents its own interference.) The lower plots with connected data points show 
cycle-by-cycle isotope ratios normalized (\%) to a cumulative running average for each ratio (right-hand y axis) during the run and illustrate how stable the signals are, even with the interferences.

The Zr isotope ratios were analyzed separately from Ti isotope ratios in several samples to measure possible mass bias effects on the $\mathrm{Zr}$ ratios. Assuming natural starting $\mathrm{Zr}$ isotope ratios, the measured mass bias was also applied in calculating the ion count rates due to the $\mathrm{Zr}^{+2}$ interferences in the Ti mass range, which were then subtracted to correct the Ti ion count rates, especially for the interference ${ }^{96} \mathrm{Zr}^{+2}$ affecting ${ }^{48} \mathrm{Ti}$ ion counts. A total of five spots were pre-sputtered in each of the six various Zircaloy samples, and several Ti isotope ratio acquisitions taken in each spot, as in the example above.

As demonstrated in the following table, the magnitude of the correction on the ${ }^{48} \mathrm{Ti}$ ion count rate is substantial in most samples, but the corrected ${ }^{49} \mathrm{Ti} /{ }^{48} \mathrm{Ti}$ ratios are within $0.7 \%$ between the various samples, and all are close to the natural value for ${ }^{49} \mathrm{Ti}^{48} \mathrm{Ti}$, which is 0.0745 . The apparent difference in the measured values below and the natural value is a typical difference termed instrument measurement or mass bias apparent in most types of mass spectrometric analysis and arises from specific instrument design parameters, fundamental elemental properties, and specifically in SIMS, slight differences in ion energies and sputtering yields. (The statistical approach to the corrections will be discussed in an upcoming report.)

One of the samples (Zr2) displays less difference between uncorrected and corrected ${ }^{49} \mathrm{Ti} /{ }^{48} \mathrm{Ti}$ ratios, and this indicates that this sample is higher in Ti impurity than the other five samples. The absolute contents of $\mathrm{Ti}$ and other impurity elements do not affect isotope ratios measurements unless the contents are altogether too low to obtain ion count rates for desired measurement precision and accuracy. Thus far, the Ti contents in these six representative samples were adequate for good measurement and good reproducibility, as shown in Table 1.

Table 1. Uncorrected and Corrected SIMS ${ }^{49} \mathrm{Ti}{ }^{48} \mathrm{Ti}$ Ratios in 6 Samples of Zircaloy

\begin{tabular}{|l|c|c|c|c||}
\hline \multicolumn{1}{|c|}{ Sample } & $\begin{array}{c}\text { Ti 49/48, Average } \\
\text { (as measured) }^{\text {(a) }}\end{array}$ & 2 SE & $\begin{array}{c}\text { Ti 49/48 Average, } \\
\text { Corrected }\end{array}$ & 2 SE, Corr \\
\hline Zr2 & 0.07108 & $7.06 \mathrm{E}-04$ & 0.07376 & $1.29 \mathrm{E}-04$ \\
\hline Zr4 & 0.06317 & $7.33 \mathrm{E}-04$ & 0.07372 & $7.38 \mathrm{E}-05$ \\
\hline TelZr4 & 0.06185 & $1.66 \mathrm{E}-03$ & 0.07353 & $1.45 \mathrm{E}-04$ \\
\hline TelZr2 & 0.05739 & $8.46 \mathrm{E}-04$ & 0.07328 & $1.51 \mathrm{E}-04$ \\
\hline TelZrNb2.5 & 0.06463 & $1.16 \mathrm{E}-03$ & 0.07362 & $1.31 \mathrm{E}-04$ \\
\hline TelZrNb3 & 0.06775 & $1.09 \mathrm{E}-03$ & 0.07364 & $1.84 \mathrm{E}-04$ \\
\hline (a) As measured ratio before correction for ${ }^{96} \mathrm{Zr}^{+2}$ interference. \\
\hline
\end{tabular}

SIMS analysis can also be used to measure impurity element abundances in most sample matrices, using different analytical settings and either using matrix-matched standards or some reasonable assumptions. Analyses are underway to determine approximate contents of $\mathrm{Ti}$ and a few selected impurity elements in the six Zircaloy samples with the goal of finding additional species that could be useful in determining irradiation levels, and to determine minimum impurity element contents for successful isotope ratio measurements. 


\subsection{Preliminary Measurements of Ti isotope Ratios in Irradiated Zircaloy}

Irradiated sample studies will be discussed in much greater detail in a subsequent deliverable, however the opportunity to analyze a sample presented itself and so the analysis was performed. A sample of irradiated Zircaloy-4 used in a tritium-producing target was available at PNNL and was assessed for measurement suitability. The level of radioactivity from one or more gamma emitters and the level of tritium in the sample, even after vacuum furnace treatments, was high relative to allowed limits for radioactive samples on the PNNL SIMS instrument. This required subdividing the sample into smaller portions for analysis. The sample was also somewhat brittle and friable, and we devised a way of mounting very small pieces, approximately 50 microns in the longest dimension, but only one at a time, pressed into high purity indium metal, which is relatively soft, and would form a conductive matrix when mounted into a typical SIMS sample holder. The sample mounting method devised utilized a highpowered optical microscope and a high-precision micromanipulator to track the microscopic sample piece and place it in position for mounting in the indium metal.

The small portion of sample was easily located by moving the SIMS sample stage around until a strong obvious $\mathrm{Zr}$ ion signal was found. Ion imaging detectors helped delineate the shape of the exposed sample piece and to precisely position the piece for analysis. The high purity Indium (In) appeared to have no measurable Ti, but to avoid ambiguities in measurements, SIMS settings were adjusted to select only ions from a small 10- or 25-micron-sized ion aperture, guided by using a real-time Zr ion image. The small piece was consumed in approximately 1 to 1.5 days' analysis time, and other sample pieces will be analyzed in the near future. A number of analyses were conducted on the sample piece, with some ${ }^{49} \mathrm{Ti} /{ }^{48} \mathrm{Ti}$ ratios definitely reflecting an irradiation effect, and others trending toward natural, possibly indicating some contamination with natural Ti during handling and mounting.

\subsection{References}

Cliff JB, DP Frank, GJ Gesh, WW Little, Jr., GH Meriwether, BD Reid, PA Simpson, CW Becker, RE Touchberry, DC Gerlach, DE Hurley and RJ Talbert. 2005. "Isotope Ratio Method Analysis of the Ford Nuclear Reactor.” National Organization of Test, Training and Research Reactors. TRTR 2005, PNNLSA-46857. Pacific Northwest National Laboratory, Richland, Washington.

Gerlach DC, JB Cliff, DE Hurley, BD Reid, WW Little, GH Meriwether, AJ Wickham and TA Simmons. 2006. "Secondary ionization mass spectrometric analysis of impurity element isotope ratios in nuclear reactor materials.” J. Surface Science 252:7041-7044.

Gesh CJ. 2004. A Graphite Isotope Ratio Method Primer: A Method for Estimating Plutonium Production in Graphite Moderated Reactors. PNNL-14568. Pacific Northwest National Laboratory, Richland, Washington.

Reid BD, DC Gerlach and PG Heasler. 2001. Trawsfynydd Plutonium Estimate. PNNL-13528. Pacific Northwest National Laboratory, Richland, Washington. 